\title{
Internet addiction among medical students of Sohag University, Egyp
}

\author{
Original \\ Rasha Abd El-Hameed Ali', Nesreen A. Mohammed ${ }^{1}$,Hanan Yousif Aly ${ }^{2}$ \\ Article \\ ${ }^{1}$ Department of Public Health and Community Medicine, Faculty of Medicine, Sohag \\ University, Sohag, Egypt \\ ${ }^{2}$ Neuropsychiatry, Faculty of Medicine, Sohag University, Sohag, Egypt
}

\begin{abstract}
Background: Internet use may have many drawbacks. Among the main threats caused by internet use is wasting time and lack of self-control over internet use, which amounts to the level of addiction with several deleterious consequences. Aim: The aim of the study is to identify the prevalence of internet addiction (IA) and associated factors among medical students in Sohag University, Egypt.

Materials and Methods: The cross-sectional survey was conducted in October 2016 and November 2016 on a random sample of 587 students selected from three medical faculties in Sohag University. The self-administered questionnaire consisted of two sections; the first section was concerned with collecting the sociodemographic data, data about student's relations and internet use characteristics; the second one aimed at assessment of the level of IA using Young's 20-item scale for IA.

Results: The findings show that the prevalence of IA was $47.7 \%$. Male sex, internet access on mobile phones, easy internet access at home, using internet for browsing social media and e-mail, and bad relation with the family were the most important predictors of IA.

Conclusion: The high prevalence of IA among medical students in Sohag University (47.7\%) is a matter of concern. Identification of factors significantly associated with IA can help in the planning of comprehensive programs to raise public awareness about the hazards and determinants of IA targeting the high-risk groups.
\end{abstract}

Received: 22 March 2017, Accepted: 12 August 2017

Key Words: Internet addiction, medical students, prevalence, risk factors.

Corresponding Author: Rasha Abd El-Hameed Ali, Department of Public Health and Community Medicine, Faculty of Medicine, Sohag University, Sohag, Egypt, Tel.: +20 114897 1563, E-mail: rashaali815@yahoo.com

ISSN: 0013-2446, Vol. 92, No.2

\section{INTRODUCTION}

Although internet was invented and developed for research purposes and information exchange, it has penetrated all aspects of life including personal communication, learning, education, research, health seeking, business, shopping, and entertainment. It has become a necessity in people's daily life ${ }^{[1]}$. A national based European study (2009) noted that $68 \%$ of people aged 16-24 years used the internet compared with $27 \%$ of people over the age of 54 years and only $10 \%$ of people over 65 years $^{[2]}$. The World Internet Users Statistics reported that the number of persons who used internet actively, especially adolescents and young people, had grown from 2.5 billion persons in 2014 to 3.7 billion persons in 2017 . Moreover, in 2017, 56.7\% of the Middle East population are active internet users who represented $3.8 \%$ of internet users worldwide ${ }^{[3-5]}$.

Internet addiction (IA) is defined as an impulse-control disorder of internet use that has an adverse impact on major life domains (e.g. interpersonal relations, physical health). IA has emerged as a universal issue, but its international estimates vary vastly ${ }^{[6]}$. Studies that investigated the prevalence rate of (IA) among students estimated that $3-13 \%$ of university students were IAs ${ }^{[7,8]}$.

Many factors are linked to IA among students such as mental predisposition, free and unlimited access to the internet ${ }^{[9]}$, social and cultural factors, and internet-specific characteristics ${ }^{[10]}$. Moreover, research that investigated IA determinants explained that lack of self-control, and social and absence of emotional ties with family were among the main psychosocial factors that underlie the $\mathrm{IA}^{[11]}$. Meanwhile, the main types of activities involved in IA are online gaming, social networking, online shopping, gambling, and virtual sex ${ }^{[12]}$.

Although the Diagnostic and Statistical Manual of Mental Disorders, 5th ed., has not included IA yet, it is an important disorder, it is often associated with many mental and psychological problems such as attention deficit, stress, anxiety and depression, and obsessive compulsive disorder ${ }^{[13]}$. Moreover, greater expenditure of both money and time on internet by IA medical students may inversely impact their academic achievements and 
result in undesirable financial consequences, putting off their healthy professional development with deleterious social consequences ${ }^{[2]}$.

Several previous studies ${ }^{[14-17]}$ suggested that IA is an important public health problem among adolescents and young adults. This study was conducted to investigate the prevalence of IA in medical students in Sohag and its associated risk factors.

\section{MATERIALS AND METHODS}

\section{Study design}

The current study is a cross-sectional study conducted among medical students of Sohag University in 2 months (October and November) duration during the academic year 2016/2017.

\section{Setting}

Sohag University is an independent University that is located in Sohag Governorate on the Eastern Nile bank. The University includes 14 faculties, among them four medical faculties (Medicine, Nursing, Pharmacy, and Veterinary Medicine, ordered chronologically from the oldest to the most recently established faculty) and there is not a Faculty of Dentistry yet. Faculties of Medicine, Pharmacy, and Nursing were chosen to be involved in the current study, while Faculty of Veterinary Medicine was excluded as it was not accessible to being outside the university compass in another city.

\section{Study population}

The studied population was composed of students of the three selected medical faculties in Sohag University which covered 4180 college students in the academic year 2016/2017.

\section{Study participants and sampling}

The sample size was calculated to be 582 students using the Open EPI program (version 3.01; Emory University Atlanta, Georgia, United States, Open Source Epidemiologic Statistics for Public Health, USA) ${ }^{[18]}$ based on the following assumptions: Prevalence of IA is $16 \%$ according to the results of a previous study conducted in El Minia governorate among secondary school students ${ }^{[14]}$, power as $80 \%$, response distribution as $50 \%$, while confidence interval and margin of error were set at 99.9 and $0.1 \%$, respectively. However, to compensate for the response rate of $80 \%$, the sample size was increased to 700 medical students.

The number of participants from each faculty was chosen by proportional allocation. Accordingly, from the Faculty of Medicine, 320 students were invited to participate in the study of whom 276 completed the questionnaire. As regards the faculty of Pharmacy, 197 completed the questionnaire out of the 240 invited students and finally, 114 students out of the 140 invited students from the faculty of Nursing completed the questionnaires. The total response rate was $83.9 \%$.

The sample was selected using a multistage stratified random technique with proportional allocation, from each faculty, stratification based on the educational grades. From each grade a clustered sample of one or two classes were selected randomly from a list that contains all classes in each grade based on the proportion of the number of students in this grade to the total number of students in the faculty. The total sample composed of all the gathered, clustered random samples from all the grades.

Inclusion criteria included: being a medical student from the selected faculties, at age ranging from 17 to 25 , being an internet user. Students who do not use the internet were excluded from the study.

\section{Data collection procedure}

At the end of their courses and after explaining the aim of the study and the questionnaire to the students in the selected classes, questionnaires were distributed to the students who accept to participate in the study and they were asked to fill them. The required time needed to fill the questionnaire was 15-20 min.

\section{Study instrument}

A structured questionnaire was used in this study, it consisted of two sections. The first section was designed to collect data including sociodemographic data (age, sex, faculty, grade level, residence, education of the parents, and their careers), relation with the parents, family members and friends, frequency of participating in physical exercises, frequency of reading, availability of computer device and internet connection at home, using internet outdoors, having a mobile phone, Facebook account and e-mail, the purpose of internet use, and duration of internet use.

The second section of the questionnaire measured the level of IA using Young's 20-item scale (YIAT 20) for IA. This scale has been widely used for screening and measuring the level of IA worldwide. The Arabic version of this scale that was applied in this study had been validated by Hawiin Lebanon ${ }^{[5]}$.

Each item of the YIAT 20 is rated on a scale from rarely to always. Using a five-point Likert scale, the responses were assigned a numeric value or score where 'rarely' was scored one point and 'always' was scored five points. These items include questions about compulsive behavior related to the use of internet, presence of problems in academic 
performance, bad home environment, relationship problems with family or friends, and suffering from emotional problems. After answering all the questions, scores of each response are added to obtain a final score ranging between 20 and 100.The higher the score, the greater the level of addiction. There is no gold standard for distinguishing between IA and non-IA. According to the IAT manual, users are given four labels based on the total score, normal user (IAT total score $\leq 20$ ), mild user (IAT total score between 20 and 49), moderate user (IAT total score between 50 and 69), and severe or excessive user (IAT total score $\geq 80$ ) ${ }^{[19]}$. Since the moderate users are often unable to control their internet use, we considered both moderate and excessive use of internet (IAT total score $\geq 50$ ) as IA and also based on the IA test manual, we considered that those who scored between 0 and 49 were normal users of internet. This notion of IA classification is fairly supported by the existing literature ${ }^{[20,21]}$ and was used for studying the suggested risk factors by $\chi^{2}$-test and for conducting regression analysis.

A pilot study was conducted on 50 medical students in the Faculty of Medicine that had not been included in the study group and the items which were not clearly understood by the students were revised and corrected.

\section{Ethical consideration}

Before starting data collection ethical approval was obtained from the Scientific Research Ethics Committee of the Faculty of Medicine, Sohag University. In addition, official approval was obtained from the deans of the three medical faculties. During the data collection stage, informed consent was secured from each participant. This also included explanation of the purpose of the study to all the participants ensuring strict confidentiality and anonymity of all the collected data.

\section{Statistical analysis}

The statistical analysis was carried out using the SPSS software for Windows (version 22.0; SPSS Inc., Chicago, Illinois, USA). Sample characteristics were summarized as numbers and percentage for categorical variables. $\chi^{2}$-Test was used for comparison between qualitative variables. The associations between IA and the studied determinants were examined at both bivariate and multivariate levels, using binary logistic regression, where IA categories were grouped as non-IA users (scored from 0 to 49), and IA users (scored from 50 to 100) to calculate odds ratios (ORs) and $95 \%$ confidence interval (CI) of the determinants of IA among students. A P value of less than 0.05 was used as the cutoff of statistical significance.

\section{RESULTS}

The current study included 587 medical students of whom 276 (47\%) were from the faculty of Medicine, 197 (33.6\%) and 114 (19.4\%) were from faculties of Pharmacy and Nursing, respectively. Regarding age, $68.8 \%$ of the participants were up to 20 years and women represented $64.4 \%$. Those who resided in urban areas were 61.8 and $54.5 \%$ of students' mothers were housewives. The availability of internet at home was reported by $82.1 \%$ of participants and $86.7 \%$ of them used mobile internet, $59.3 \%$ had their own computers, 88.2 and $92 \%$ had an e-mail and social media accounts, respectively, and 64.6\% of them have used internet for less than 5 years.

The most common purpose of internet use among the studied students was social media $(80.2 \%)$ followed by news $(69.3 \%)$, scientific research $(69.2 \%)$, entertainment $(57.9 \%)$, checking e-mail $(50.9 \%)$, gaming $(35.1 \%)$, and finally shopping (18.9\%) (Fig. 1).

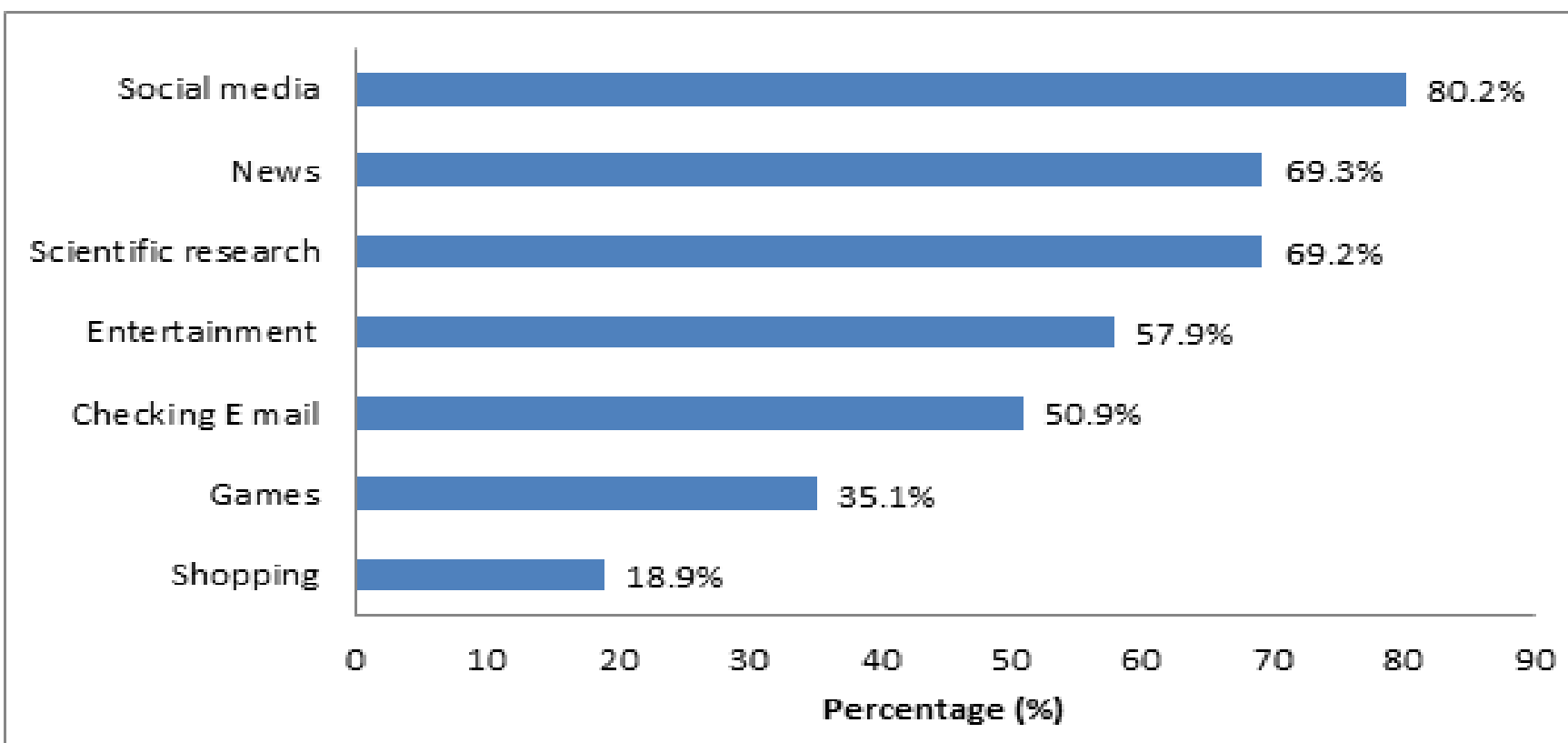

Fig. 1: Purposes of internet use among the studied medical students of Sohag University, academic year 2016-2017. 
were mild users (score between 20 and 49); 43.6\% were classified as moderate addicts (score 50-79); and those who were severe addicts represented $4.1 \%$ of participants with a score of at least 80 (Fig. 2).

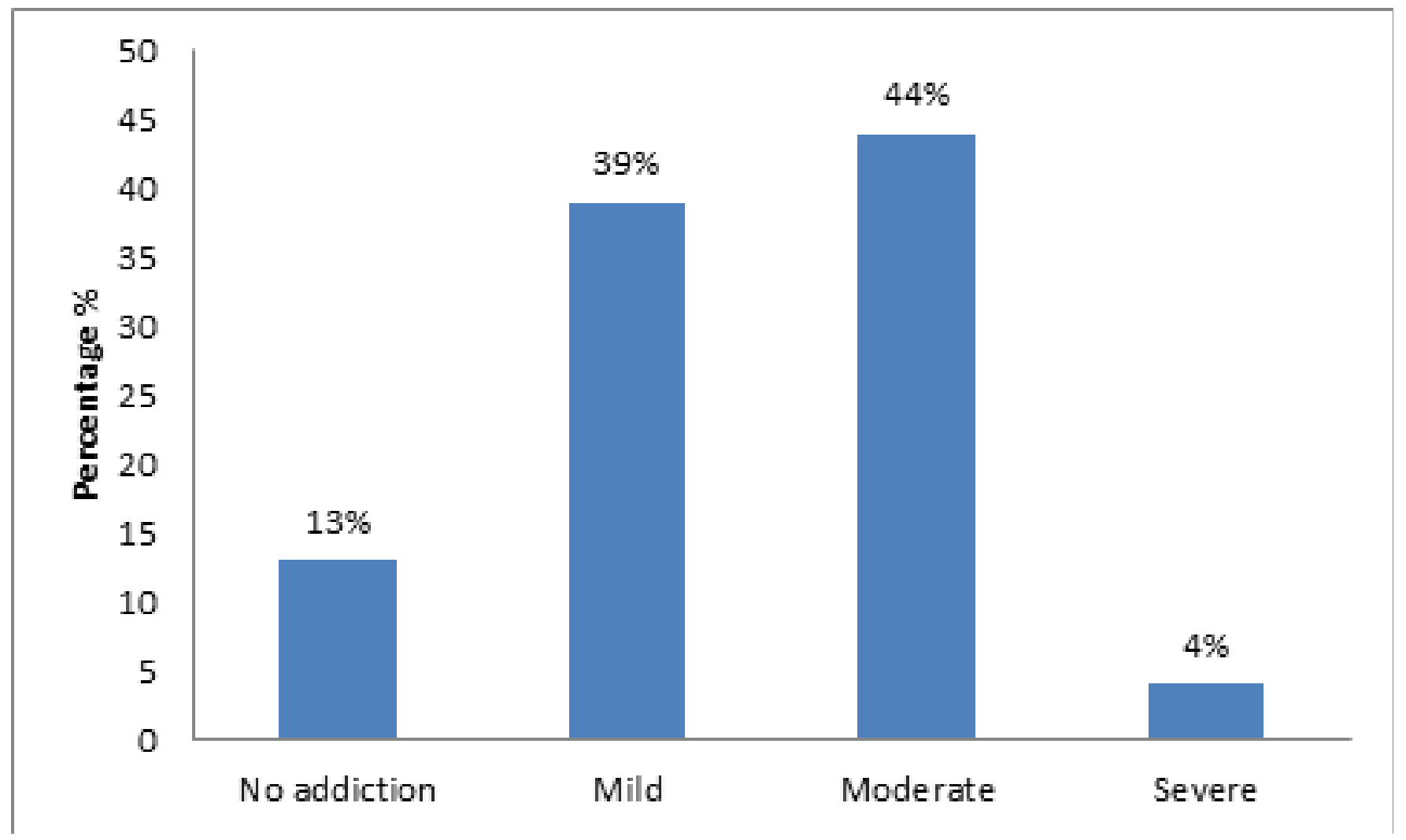

Fig.2: Distribution of the studied medical students according to IA level

Students classified as moderate and severe IAs were considered IA users (scored from 50 to 100) and represented $47.7 \%$ of participants and those with lower scores were considered as nonIA. Sex significantly affected IA where there were significantly more male addicts than women (56.9 vs. $42.6 \%, P<0.01)$. Moreover, mother's occupation and family relations were found to be significantly associated with IA $(P<0.01)$ where the percentage of addicted participants who had working mothers was significantly higher than those whose mothers were housewives (55.1 vs. $41.6 \%, P=0.001$ ), and the percentage of addicted participants who had bad family relations was significantly higher than that of addicts with good family relations ( 61.2 vs. $44.6 \%$, $P=0.001)$. There was no significant difference between IAs and non-IA with regard to age and residence $(P=0.074$ and 0.2 , respectively).

Table 1: Relationship between internet addiction and sociodemographic characteristics, family relations, and internet-specific characteristics of the studied medical students, Sohag University, 2016/2017

\begin{tabular}{|c|c|c|c|}
\hline \multicolumn{4}{|c|}{ IA $[\mathrm{n}(\%)]$} \\
\hline Characteristics & Noninternet addicted [307 (52.3)] & Internet addicted [280 (47.7)] & $P$ value \\
\hline \multicolumn{4}{|l|}{ Age (years) } \\
\hline$\leq 20$ & $201(49.8)$ & $203(50.2)$ & 0.074 \\
\hline$>20$ & $106(57.9)$ & $77(42.1)$ & \\
\hline \multicolumn{4}{|l|}{ Sex } \\
\hline Female & $217(57.4)$ & $161(42.6)$ & $0.001^{* *}$ \\
\hline Male & $90(43.1)$ & $119(56.9)$ & \\
\hline
\end{tabular}

Furthermore, a significant association was found between IA and some factors such as owning computers $(P=0.005)$, having internet at home, using mobile internet, having an e-mail, and using internet for more than 5 years $(P<0.0001)$.

In addition, $41.8 \%$ of students with social media accounts were IAs compared with $23.4 \%$ of those who did not have an account $(P=0.001)$. Regarding internet use purposes among the surveyed students, a statistically significant difference was found between IAs and non-IAs regarding most purposes where $59.1 \%$ of students who did not use internet for scientific research were IA compared with $42.6 \%$ of students who used internet for this purpose $(P<0.0001)$. Moreover, browsing social media, entertainment, checking e-mails, gaming, and shopping purposes were shown to have a significant effect on IA (Table 1). 
Residence

$\begin{array}{ll}\text { Urban } & 182(50.1) \\ \text { Rural } & 125(55.8)\end{array}$

$181(49.9)$

0.202

Father occupation

Governmental sector

Private sector

Others

Mother occupation

$$
\begin{gathered}
\text { Housewife } \\
\text { Working }
\end{gathered}
$$

Family relation

Bad

Computer at home

No

I have my own computer

Internet at home

$$
\text { Yes }
$$

No

Using Internet on your mobile phone

$$
\begin{gathered}
\text { I do not have a mobile phone } \\
\text { I do not use mobile internet } \\
\text { I use mobile internet }
\end{gathered}
$$

Having an e-mail

Yes
No

Having an account on the social media

$$
\text { Yes }
$$$$
\text { No }
$$

Time since first internet use (years)

$$
\begin{aligned}
& \leq 5 \\
& >5
\end{aligned}
$$

Purpose of internet use

Scientific research and education

$$
\begin{aligned}
& \text { Yes } \\
& \text { No }
\end{aligned}
$$

Social media (Facebook, Twitter, etc.)

$\begin{array}{ll}\text { Yes } & 226(48) \\ \text { No } & 81(69.8)\end{array}$

Entertainment (movies and songs)

$\begin{array}{ll}\text { Yes } & 158(46.5) \\ \text { No } & 149(60.3)\end{array}$

$106(54.6)$

$5(83.3)$
99 (44.2)

$214(50.1)$

0.160

26 (41.3)

40 (41.2)

133 (41.6)

$0.001 * *$

147 (55.1)

64 (62.1)

$0.001 * *$

216 (44.6)

12 (26.7)

$0.005 * *$

88 (45.4)

180 (51.7)

247 (51.2)

$0.000 * *$

33 (31.4)

1 (16.7)

$0.000 * *$

18 (25)

$261(51.3)$

263 (50.8)

$0.000 * *$

17 (24.6)

269 (49.8)

$0.001 * *$

11 (23.4)

157 (41.4)

$0.000 * *$

123 (59.1)

$173(42.6)$

$0.000 * *$

107 (59.1)

245 (52)

$0.000 * *$

35 (30.2)

182 (53.5)

$0.001 * *$

98 (39.7)

Games 


$\begin{array}{cccc}\text { Yes } & 93(45.1) & 113(54.9) & 0.012^{*} \\ \text { No } & 214(56.2) & 167(43.8) & \\ \text { Yes } & 130(43.5) & 169(56.5) & 0.000^{* *} \\ \text { No } & 177(61.5) & 111(38.5) & 0.011^{*} \\ & & & \\ \text { Yes } & 46(41.4) & 65(58.6) & 0.077 \\ \text { No } & 261(54.8) & 215(45.2) & \\ \text { Yes } & & & \\ \text { No } & 203(49.9) & 76(42.2) & \end{array}$

\section{$* P<0.05$, significant.}

$* * P<0.01$, significant.

On univariate logistic regression analysis, most of the studied variables were significantly associated with IA. Multiple regression analysis was performed for variables that were significantly associated with IA in the univariate analysis model and identified that using mobile internet, checking e-mail, male sex, social media browsing, presence of internet at home, bad family relations, and internet use for more than 5 years are independent strong predictors of IA. Remarkably, the use of internet for scientific research purpose was inversely associated with IA, as shown in Table 2 .

Table 2: Final model of multiple logistic regression of factors predicting internet addiction among the studied medical students, Sohag University, 2016/2017

\begin{tabular}{llcl}
\hline Characteristics & OR & $95 \%$ CI & $P$-value \\
\hline $\begin{array}{l}\text { Using internet for scientific } \\
\text { research and education }\end{array}$ & 0.5 & $0.3-0.7$ & $0.000^{* *}$ \\
$\quad \begin{array}{l}\text { Using internet on your } \\
\quad \text { mobile phone }\end{array}$ & 2.3 & $1.3-3.9$ & $0.003^{* *}$ \\
$\quad \begin{array}{l}\text { Using internet for } \\
\text { checking e-mail }\end{array}$ & 1.7 & $1.2-2.5$ & $0.004^{* *}$ \\
$\quad$ Family relations & 1.9 & $1.2-3.09$ & $0.005^{* *}$ \\
$\quad$ Sex & 1.5 & $1.03-2.2$ & $0.033^{*}$ \\
Using internet for social media & 1.9 & $1.2-3.1$ & $0.009^{* *}$ \\
$\quad$ Internet at home & 1.8 & $1.1-2.9$ & $0.023^{*}$ \\
$\quad$ Time since first internet use & 1.5 & $1.01-2.2$ & $0.044^{*}$ \\
\hline
\end{tabular}

CI, confidence interval; OR, odds ratio.

$* P<0.05$, significant

$* * P<0.01$, significant. 


\section{DISCUSSION}

It is generally agreed that the internet plays an important role in our life. A growing body of literature had examined the prevalence and risk factors of IA among adolescents and young adults worldwide. In Egypt, few studies had been conducted for this purpose ${ }^{[14-16]}$. In our study, 587 medical students were surveyed to identify the prevalence of IA and to broaden our knowledge about its risk factors.

On assessment of the purpose of internet use among the surveyed medical students, social media comes first followed by news, scientific research, entertainment, checking an e-mail, playing games, and finally shopping. Several studies are consistent with our findings ${ }^{[15,22]}$, even though Nath et al. ${ }^{[23]}$ found that $86.7 \%$ of the surveyed medical students were using the internet mainly for nonacademic purposes (social networking and downloading media).

The current study has shown that approximately half $(47.7 \%)$ of the surveyed medical students suffered from IA, of whom $4.1 \%$ had severe addiction, while the remaining $53.3 \%$ were normal internet users. These findings are in line with two studies in Menoufia University ${ }^{[15,16]}$. Shaheen et $a l .{ }^{[15]}$ found that $48.5 \%$ of the medical students were pathological internet users, and Desouky and Ibrahem ${ }^{[16]}$ noted that $13.2 \%$ of both medical and nonmedical students were problematic internet users and $39.1 \%$ were potentially problematic internet users.

These results are also close to the findings of Al-Gamal et $a l^{[20]}$ in Jordan (40\%). Our findings are also consistent with the results of two studies in India, which reported that $46.8 \%$ and $44.6 \%$ of the respondents had IA of whom 0.5 and $3.07 \%$ were severe IAs, respectively ${ }^{[23,24]}$. Several studies in Iran, Turkey, and Tunisia found that 16.9, 18.8, and $28.7 \%$ of the respondents had $\mathrm{IA}^{[3,17,25]}$.

The foremost cause of the discrepancy in figures between our study and other studies may be due to lack of certain definition and exact assessment of IA, besides various samples and tools assigned and variation in social backgrounds. Moreover, IA prevalence was higher in countries with greater traffic time consumption, pollution, and poor life quality in general ${ }^{[26]}$.

With regard to risk factors of IA, our study revealed that sex was significantly associated with IA where men were 1.5 -folds at increased risk of IA than women $(\mathrm{OR}=1.5$; 95\% CI: 1.3-2.2). Contrary to our results, Kim et al..$^{[27]}$ noted that a change in the availability of internet removed sex difference, while the findings of several studies are consistent with our results ${ }^{[23,28-33]}$. A possible explanation is that men receive less parental supervision and they use the internet for entertainment purposes more than women. Morahan-Martin and Schumacker ${ }^{[34]}$ explained sex difference in IA by the fact that men are involved more in online activities such as gaming and pornography which may lead to IA.
In agreement with our findings many previous researchers reported the absence of significant relation between IA and age $e^{[1,15,28,31,35]}$. Contrary to age, time since first use of internet was significantly associated with IA risk. Similar to other studies ${ }^{[16,23,36]}$, we found that using internet for more than 5 years was significantly associated with IA. This may be explained by the increasing availability of applications and services provided online that made internet a necessity in life.

Family influences the development and well-being of children and adolescents. Yen et al. ${ }^{[32]}$ mentioned that IA in adolescents could be expected by the presence of conflict between the parents and adolescents. This might be attributed to adolescents' resistance to the supervision of parents, and their rejection of the presence of fixed rules of internet use. This is in agreement with our results that highlights the significant association between poor family relationships and increased risk of IA $(\mathrm{OR}=1.9 ; 95 \% \mathrm{CI}$ : 2.2-3.9). Correspondingly, Kilic et al. ${ }^{[17]}$ indicated that IA was uncommon among those having good family relations and enjoying family support.

Several variables control availability and duration of internet use and hence the risk of IA. Among those variables, the presence of a computer and an internet connection at home, which both make internet access easy, were both found to be significantly associated with IA. Further analysis showed that those having their own computer were 1.5 -folds at increased risk of IA, and the availability of internet at home raised IA risk to 2.3 -folds. These findings are in line with some studies that reported that internet access at home was a significant predictor of $\mathrm{IA}^{[14,15,33]}$. The presence of various applications and the enhanced functionality of smartphones had made them act as a full-blown computer and an information provider ${ }^{[37]}$. Moreover, in the current study among the surveyed medical students $99 \%$ had mobile phones and $86.7 \%$ accessed the internet on their mobile phone. In agreement with many studies, we found strong evidence of significant association between using internet on mobile phone and IA, attracting attention to the hazards of prolonged use of smartphones $^{[1,15,23]}$.

Previous literature ${ }^{[1,16,28,36,38,39]}$ support our results that using internet for social media browsing, checking e-mail, entertainment, and shopping, were significantly associated with IA. Besides, supported by the findings of previous studies we found that medical students who used the internet for social media browsing were at a higher risk of IA than those who did not ${ }^{[24,33]}$. These findings can be explained by the nature of social media which provides a means for social interaction and establishment of social relations. On the other hand, IA was found to be inversely associated with using internet for scientific research, which is supported by the findings of Kormas et al..$^{[36]}$, while Balhara et $a l .{ }^{[38]}$ and Prievara et al. ${ }^{[39]}$ found no significant association between IA and the use of internet for academic research purpose. 


\section{LIMITATIONS}

This study has many notable strengths; first we approached medical students in whom detection of high level of IA is assumed to be of a great importance as it indicates that IA among nonmedical students will be greater. We used YIAT 20 which is the most reliable and most commonly used tool in the assessment of IA and its Arabic version is previously validated. Furthermore, the appropriate sample size, high response rate together with the random assignment of participants ensure a representative sample of medical students.

With regard to limitations, the most important limitation is our reliance on self-reporting of the surveyed students; we did not use confirmatory clinical diagnosis of IA.

\section{CONCLUSION AND RECOMMENDATIONS}

This study highlights the troubling reality of the high prevalence of IA among medical students in Sohag University (43.6\% including $4.1 \%$ who had severe IA). Male sex, access to the internet on mobile phones, easy internet access at home, using the internet for browsing social media and e-mail, and bad relationships with the family were the most important predictors of IA. Using internet for scientific researches and academic purposes was inversely associated with IA.

Comprehensive programs should be formulated to raise public awareness about the hazards and determinants of IA, emphasizing on targeting men, adolescents, and young adults on one side, and the detection of those potential IAs prior to their conversion to addicts on the other side. Students need to be educated about safe, valuable, and healthy practice of internet use to overcome the anticipated increase in IA among young adults in Egypt.

\section{ACKNOWLEDGEMENTS}

The authors thank Dr Nazir for sending his validated Arabic version of YIAT 20 and the students of the faculties of Medicine, Pharmacy, and Nursing for their cooperation in completing the questionnaires needed for conducting the research.

\section{CONFLICT OF INTEREST}

Authors have no conflict of interests, and the work was not supported or funded by any drug company.

\section{REFERENCES}

1. Chaudhari B, Menon P, Saldanha D, Tewari A, Bhattacharya L. Internet addiction and its determinants among medical students. Ind Psychiatry J 2015; 24:158-162.
2. Gracia E, Herrero J. Internet use and self-rated health among older people: A National Survey. J Med Internet Res 2009; 11:e49.

3. Internet World Stats. Internet users of the world: distribution by world regions 2014. Available at: http://www.internetworldstats. [Accessed 27 February 2016].

4. Internet World Stats. World Internet users statistics: Distribution by world regions 2017. Available at: http://www.internetworldstats. [Accessed 31 March 2017].

5. Hawi NS. Arabic validation of the Internet addiction test. Cyberpsychol Behav Soc Netw 2013; 16:200-204.

6. Wang Y, Wu AMS, Lau JTF. The health belief model and number of peers with internet addiction as interrelated factors of Internet addiction among secondary school students in Hong Kong. BMC Public Health 2016; 16:272.

7. Lai CM, H W, Ang RP, Pang JS, Ho RC Psychometric properties of the Internet Addiction Test in Chinese adolescents. J Pediatr Psychol 2013; 38:794-807.

8. Malviya A, Dixit S, Shukla H, Mishra A, Jain A, Tripathi A. A study to evaluate internet addiction disorder among students of a medical college and associated hospital of Central India. Community Med 2014; 5:93-95.

9. Sharma A, Sahu R, Kasar PK, Sharma R. Internet addiction among professional courses students: a study from Central India. Int J Med Sci Public Health 2014; 3:1069-1073.

10. Marahatta SB, Adhikari B, Aryal N, Regmi R. Internet addiction and associated factors among health sciences students in Nepal. J Community Med Health Educ 2015; 5:362.

11. Bahrainian SA, Alizadeh KH, Raeisoon MR, Gorji $\mathrm{OH}$, Khazaee A. Relationship of Internet addiction with self-esteem and depression in university students. J Prev Med Hyg 2014; 55:86-89.

12. Wu CY, Lee MB, Liao SC, Chang LR. Risk factors of Internet addiction among internet users: an online questionnaire survey. PLoS One 2015; 10:1-10

13. MusarratA, RashidBK, Muhammad S, Muhammad B, Altaf H, Mehvish H. The relationship between internet addiction and anxiety among students of 
University of Sargodha. Int J Humanit Soc Sci 2014; 4:288-293.

14. Kamal NN, Mosallem FA. Determinants of problematic internet use among El Minia high school students, Egypt. Int J Prev Med 2013; 4:1429-1437.

15. Shaheen HM, Farahat TM, Gaber HM. Problematic internet use among medical school students in Menoufia University Egypt. J Child Adolesc Behav 2016; 4:298.

16. Desouky DE, Ibrahem RA. Internet addiction and psychological morbidity among Menoufia University students, Egypt. Am J Public Health Res 2015; 3:192-198.

17. Kilic M, Avci D, Uzuncakmak T. Internet addiction in high school students in Turkey and multivariate analyses of the underlying factors. J Addict Nurs $2016 ; 27: 39-46$.

18. Dean AG, Sullivan KM, Soe MM. OpenEpi: Open source epidemiologic statistics for public health, version 3.01. Available at: http://www.OpenEpi. com.

19. Widyanto L, McMurran M. The psychometric properties of the internet addiction test. Cyberpsychol Behav J 2004; 7:443-450.

20. Al-Gamal E, Alzayyat A, Ahmad MM. Prevalence of internet addiction and its association with psychological distress and coping strategies among university students in Jordan. Perspect Psychiatr Care 2015; 52:49-61.

21. Ghamari F, Mohammadbeigi A, Salehi NM, Hashiani AA. Internet addiction and modeling its risk factors in medical students, Iran. Indian $\mathbf{J}$ Psychol Med 2011; 22:158-162.

22. Capetillo-Ventura N, Juárez-Treviño M. Internet addiction in university medical students. Med Univers 2015; 17:88-93.

23. Nath K, Naskar S, Victor R. A cross-sectional study on the prevalence, risk factors, and ill effects of internet addiction among medical students in Northeastern India. Prim Care Companion CNS Disord 2016; 18:2.

24. Pramanik T, Sherpa MT, Shrestha R. Internet addiction in a group of medical students: a cross sectional study. Nepal Med Coll J 2012; 14:46-48.

25. Chérif L, Ayedi H, Hadjkacem I, Khemekhem K, Khemekhem S, Walha A, et al. Problematic Internet use among teenagers in Sfax, Tunisia. Encephale 2015; 41:487-492.
26. Cheng C, Li AY. Internet addiction prevalence and quality of (real) life: a meta-analysis of 31 nations across seven world regions. Cyberpsychol Behav Soc Netw 2014; 17:755-760.

27. Kim K, Ryu E, Chon MY, Yeun EJ, Choi SY. Internet addiction in Korean adolescents and its relation to depression and suicidal ideation: A questionnaire survey. Int J Nurs Stud 2006; 43:185-192.

28. Tayyar S, Seva O, Oner Kurt A, Yapici G, Yazici AE, Bugdayci R, et al. Prevalence and risk factors of Internet addiction in high school students. Eur J Public Health 2013; 24:15-20.

29. Asiri S, Fallahi F, Ghanbari A, Kazemnejad-Leili E. Internet addiction and its predictors in guilan medical sciences students. Nurs Midwifery Stud $2013 ; 2: 234-239$.

30. Bener A, Bhugra D. Lifestyle and depressive risk factors associated with problematicinternet use in adolescents in an Arabian Gulf culture. J Addict Med 2013; 7:236-242.

31. Ghamari F, Mohammadbeigi A, Mohammadsalehi $\mathrm{N}$, Hashiani AA. Internet addiction and modeling its risk factors in medical students, Iran. Indian J Psychol Med 2011; 33:158-162.

32. Yen JY, Yen CF, Chen $\mathrm{CC}$, Chen $\mathrm{SH}, \mathrm{Ko} \mathrm{CH}$ Family factors of internet addiction and substance use experience in Taiwanese adolescents. Cyberpsychol Behav 2007; 10:323-329.

33. Ak S, Koruklu N, Yilmaz Y. A study on Turkish adolescent's internet use: possible predictors of internet addiction. Cyberpsychol Behav Soc Netw 2013; 16:205-209.

34. Morahan-Martin JM, Schumacker P. Incidence and correlates of pathological internet use. Comput Human Behav 2000; 16:13-29.

35. Islam MA, Hossin MZ. Prevalence and risk factors of problematic internet use and the associated psychological distress among graduate students of Bangladesh. Asian J Gambl Issues Public Health 2016; 6:11.

36. Kormas G, Critselis E, Janikian M, Kafetzis D, Tsitsika A. Risk factors and psychosocial characteristics of potential problematic and problematic internet use among adolescents: a cross-sectional study. BMC Public Health 2011; 11:595. 
37. Suliman SA, Mohammad FA, Ismael SA, Salaheldin FB, Adel SA. Smartphone addiction among university students in the light of some variables. Comput Human Behav 2016; 61:155164.

38. Balhara YP, Gupta R, Atilola O, Knez R, Mohorović T, Gajdhar W, et al. Problematic internet use and its correlates among students from three medical schools across three countries Acad Psychiatry 2015; 39:634-638.

39. Prievara DK, Pikó B. Being online without a purpose - study of background variables of problematic Internet use. Psychiatr Hung 2016; 31:146-156.. 